\title{
Strategies for immune regulation in iPS cell-based cardiac regenerative medicine
}

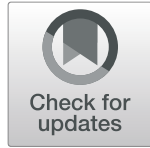

Kozue Murata ${ }^{1,2}$, Masaya Ikegawa ${ }^{3}$, Kenji Minatoya ${ }^{2,4}$ and Hidetoshi Masumoto 1,4*

\begin{abstract}
Cardiac regenerative therapy is expected to be a promising therapeutic option for the treatment of severe cardiovascular diseases. Artificial tissues or organoids made from cardiovascular cell lineages differentiated from human induced pluripotent stem cells (iPSCs) are expected to regenerate the damaged heart. Even though immune rejection rarely occurs when iPSC-derived graft and the recipient have the same HLA type, in some cases, such as tissue transplantation onto hearts, the HLA matching would not be sufficient to fully control immune rejection. The present review introduces recent immunomodulatory strategies in iPSC-based transplantation therapies other than MHC matching including the induction of immune tolerance through iPSC-derived antigenpresenting cells, simultaneous transplantation of syngeneic mesenchymal stem cells, and using the universal donor cells such as gene editing-based HLA modulation in iPSCs to regulate T cell compatibility. In addition, we present future perspectives for proper adjustment of immunosuppression therapy after IPSC-derived tissue/organoid-based cardiac regenerative therapies by identifying biomarkers monitoring immune rejection.
\end{abstract}

Keywords: Induced pluripotent stem cells, Transplantation, Immune regulation, Cardiac regeneration

\section{Introduction}

Cardiovascular diseases are leading causes of death and medical expenditure worldwide even recent progresses in medical treatments [1]. Therapeutic modalities in severe heart diseases should be further investigated considering that chances in heart transplantation are quite limited due to donor shortage [2], and ventricular assist devices for circulatory support are not anticipated for long-term use due to complications such as thromboembolism, hemorrhage, and infection so far [3,4]. Regenerative medicine is an emerging therapeutic option to provide new approaches in current cardiovascular medicine [5-8]. One of the key concepts in cardiac regenerative medicine is the supplementation of exogenous stem cells

\footnotetext{
* Correspondence: hidetoshi.masumoto@riken.jp

${ }^{1}$ Clinical Translational Research Program, RIKEN Center for Biosystems Dynamics Research, 2-2-3 Minatojima-minamimachi, Chuo-ku, Kobe, Hyogo 650-0047, Japan

${ }^{4}$ Department of Cardiovascular Surgery, Graduate School of Medicine, Kyoto University, Kyoto, Japan

Full list of author information is available at the end of the article
}

and the derivatives in cardiovascular cell lineages to restore damaged heart tissue structure and function [7, 9-13]. Pluripotent stem cells are expected to be promising cell sources in regenerative medicine for various intractable diseases by virtue of the theoretically infinite proliferative capacity and ability to differentiate into various types of somatic cells [14]. Especially, human induced pluripotent stem cells (iPSCs) are expected to mitigate immune rejection after cell/tissue transplantation in autologous or human leucocyte antigen (HLA)-controlled allogeneic use which has been investigated in various animal allogeneic transplantation models $[15,16]$ and clinical studies. Immune [17] regulation in human iPSC-based cardiac regenerative therapy allowing graft survival without immunological complications should be further investigated and clinically validated for the standardization of human iPSC-based regenerative medicine in the future. In the present review, we introduce possible strategies for immune regulation in human iPSC-based cardiac regenerative therapy.

(c) The Author(s). 2020 Open Access This article is licensed under a Creative Commons Attribution 4.0 International License, which permits use, sharing, adaptation, distribution and reproduction in any medium or format, as long as you give

appropriate credit to the original author(s) and the source, provide a link to the Creative Commons licence, and indicate if changes were made. The images or other third party material in this article are included in the article's Creative Commons licence, unless indicated otherwise in a credit line to the material. If material is not included in the article's Creative Commons licence and your intended use is not permitted by statutory regulation or exceeds the permitted use, you will need to obtain permission directly from the copyright holder. To view a copy of this licence, visit http://creativecommons.org/licenses/by/4.0/ 


\section{Possible immunological problems in iPSC-based cardiac regenerative therapy}

An immunological privilege of iPSCs in regenerative medicine is that autologous iPSCs which are considered to be immunologically identical with the host can be established from the host somatic cells and used for transplantation therapies [17]. However, the establishment of autologous iPSCs from each patient validated for clinical use would be costly and time-consuming which would hamper the standardization of the therapy. Alternatively, Kyoto University and the collaborators have been promoting a project to prepare and stock clinical-grade allogeneic iPSCs from the lymphocytes of HLA-homozygous healthy donors which would be less susceptible for immune rejection [18]. Established stocks of HLA-homozygous iPSCs were reported to cover approximately $32 \%$ of the Japanese population for use in clinical studies for various target diseases by 2018 [18].

Several allogeneic transplant models have been tested to validate whether the use of HLA-homozygous iPSCs can mitigate immune rejection. The experiments using cynomolgus monkeys demonstrated that immune rejection is rarely detected in allograft transplantation differentiated from major histocompatibility complex (MHC) type-matched iPSC. In transplantation experiments of retinal pigment epithelial (RPE) cells derived from monkey MHC-homozygous iPSCs, fair engraftment of RPE cells transplanted to MHC-matched animal models was confirmed without the use of immunosuppressants [15]. Another report showed that the dopamine neurons differentiated from iPSCs derived from cynomolgus macaques with homozygous MHC haplotypes were transplanted to monkeys in which at least one of the alleles was identical to the allografts. Consequently, fair survival of grafted MHC-matching dopamine neurons was observed along with the suppression in the accumulation of microglia and lymphocytes into the grafts [16]. In iPSC-based cardiac regeneration, Shiba et al. reported an allogeneic transplantation model using cynomolgus monkeys (Macaca fascicularis). iPSCs from MHChomozygous animals were differentiated into cardiomyocytes (iPSC-CMs) and subsequently transplanted to MHC-matched monkeys by direct intramyocardial injection. The grafted cardiomyocytes showed electrically coupling to the host heart and survived without immune rejection in monkeys treated with clinically relevant doses of immunosuppressants, whereas the transplantation of iPSC-CMs to MHC-mismatched monkeys even treated with immunosuppressants exhibited immune rejection of grafted cardiomyocytes with severe infiltration of T lymphocytes [19].

On the other hand, the benefits of MHC-matching seem to be alleviated in transplantation of iPSC-derived bioengineered heart tissues which is a promising strategy in cardiac regenerative medicine to promote therapeutic efficiency [20-23]. Kawamura et al. reported a cynomolgus monkey-based allogeneic transplantation experiment using cell sheets prepared from iPSC-CMs. In the experiments, monkeys with immunosuppressants could show fair engraftment of iPSC-CM sheets regardless of MHCmatching, whereas even $\mathrm{MHC}$-matched iPSC-CM sheets could not be sufficiently engrafted without immunosuppressants [24]. The results in allogeneic transplantation would be attributed by the presence of minor antigens and may indicate that the significance of $\mathrm{MHC}$ matching would be attenuated in iPSC-based cardiac regenerative therapy. In iPSC-based cardiac regenerative therapy through heart tissue transplantation, it might be assumed that strategies beyond HLA-matching would be required for broad prevalence of the transplantation therapy.

\section{Emerging strategies for immune regulation in iPSC-based transplantation}

In this context, several attempts have been made to overcome immune rejection through strategies other than HLA-matching so far. One of the promising strategies is the induction of immune tolerance in iPSCbased transplantation. There are two pathways in immune tolerance: central pathway by selective elimination of self-antigenic immune cells in the thymus and bone marrow and peripheral pathway. An important mechanism for this peripheral pathway of immune tolerance is the immunosuppression mediated by regulatory $\mathrm{T}$ cells (Tregs) (Fig. 1a). Tregs have $\mathrm{T}$ cell receptors and receive antigen presentation, but do not produce IL-2, which is important for $\mathrm{T}$ cell differentiation, proliferation, and maintenance. On the other hand, Tregs express CD25, a receptor with high affinity for IL-2. In addition, they express cytotoxic $T$ lymphocyte antigen-4 (CTLA4) which competitively inhibits the binding between active $\mathrm{T}$ cells and CD80/86 of antigen-presenting cells. Based on these features, immune tolerance is established by suppressing $\mathrm{T}$ cell co-stimulation and IL-2-induced proliferation of active T cells (Fig. 2b) [25, 26]. The induction of graft-specific Treg-dependent peripheral immune tolerance in liver transplantation is reported to improve the graft viability without the use of immunosuppressants [27, 28]. In iPSC-based transplantation therapies, it would be a possible approach to establish immune tolerance by increasing the total number of Tregs or augmenting the proportion of Tregs through elimination of immune cells causing immune rejection.

Therapeutic approaches for the establishment of immune tolerance are reported so far (Table 1). Otsuka et al. efficiently differentiated thymic epithelial cells from iPSCs (iPSC-TECs) which worked as thymic antigenpresenting cells to induce donor-specific immune 

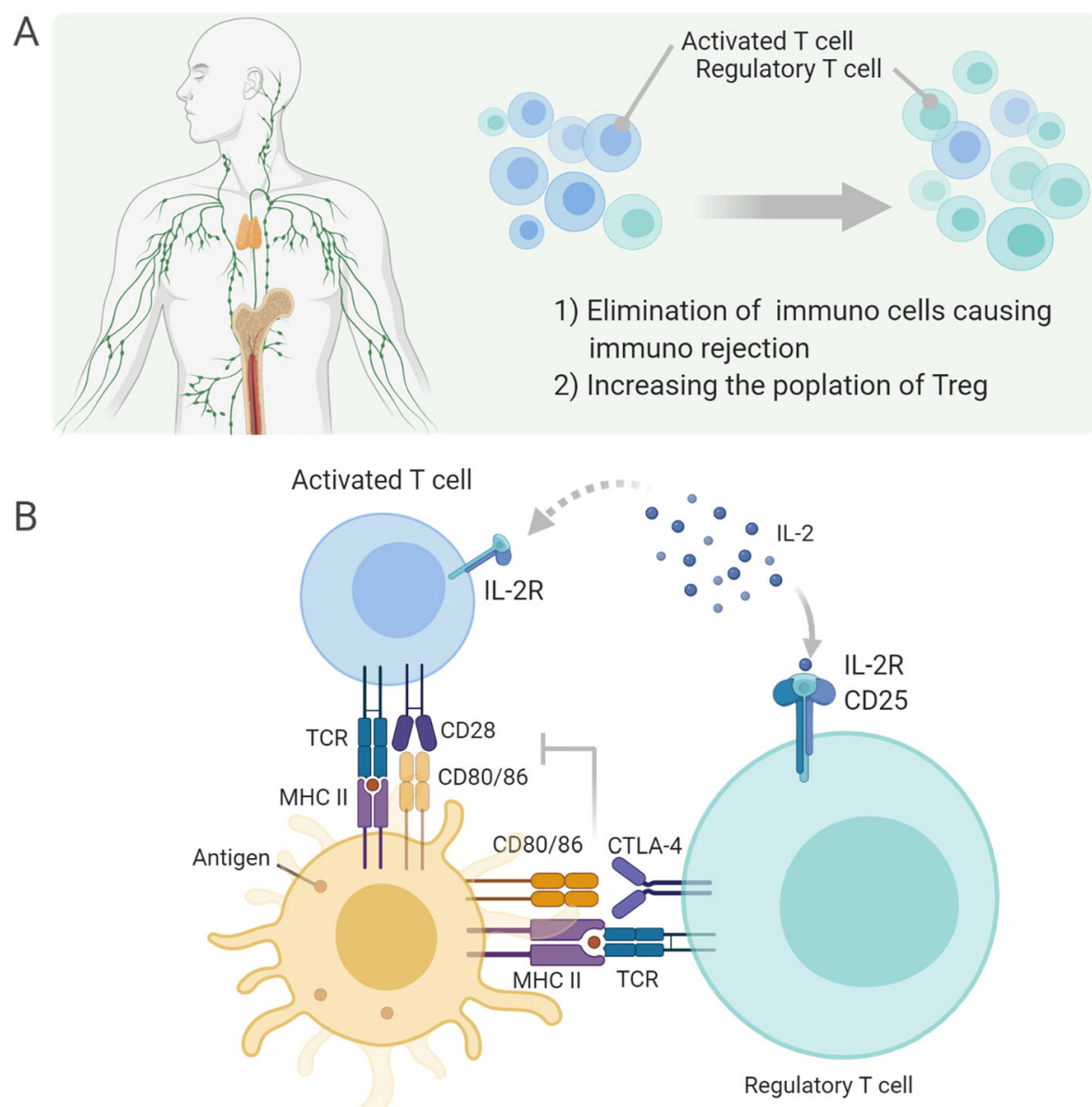

Fig. 1 Mechanisms of immunosuppression induced by Treg. a Treg establishes immune tolerance by inhibiting the activation and proliferation of immune cells that cause immune rejection. In addition, the high sensitivity of $\mathrm{IL}-2$ causes Treg to selectively proliferate and increases the Treg population. $\mathbf{b} \mathrm{IL}-2$ is a cytokine essential for $\mathrm{T}$ cell differentiation, proliferation, and maintenance and binds to $\mathrm{IL}-2 \mathrm{R}$; $\mathrm{IL}-2$ is more likely to bind in the presence of CD25; Treg expresses high levels of CD25; Treg reduces the expression of CD80/86 in antigen-presenting cells. In addition, Treg suppresses the CD80/86 co-stimulation to T cells as a result of the high expression of CTLA-4, which is prone to bind CD80/86

tolerance. In an allogeneic transplantation model, transplantation of iPSC-TECs in advance of the transplantation of skin allografts with identical MHCs with iPSC-TECs resulted in prolonged graft survival (Fig. 2a) [29].

In addition to the induction of immune tolerance by antigen-presenting cells of identical MHC type, tolerance induction using syngeneic mesenchymal stem cells (MSCs) has also been reported (Fig. 2b). Yoshida et al. revealed that simultaneous transplantation of iPSC-derived transplants and syngeneic MSCs increased the expression of anti-inflammatory cytokines TGF $\beta$ and IL-2 and then induced Treg. In addition, the simultaneous transplantation of MSCs accelerated the apoptosis of $\mathrm{CD}^{+}$cytotoxic $\mathrm{T}$ cells against the transplants which accordingly achieved the induction of immune torelance [30].

Another intriguing approach is HLA modulation in iPSCs to regulate $\mathrm{T}$ cell compatibility which depends on
HLA types (Fig. 2c). Xu et al. used a gene-editing technology with CRISPR-Cas9 system to selectively deplete HLA-A and HLA-B on chr.6 of iPSCs to prevent immune responses from $\mathrm{CD}^{+}$cytotoxic $\mathrm{T}$ cells. The modulated iPSCs were also protected from immune responses from natural killer cells because HLA-C, HLAE, HLA-F, and HLA-G were preserved. Differentiated cells from the modulated iPSCs would be considered as an immunologically ideal cell source for transplantation therapies with enhanced immunocompatibility suppressing immune rejection after transplantation. It is also estimated that only 12 strains of iPSCs with HLA modulation theoretically cover more than 90\% of the population worldwide which encourages the establishment of clinical-grade human iPSC bank covering almost all mankind [31]. Even though considerations on off-target mutation risk regarding gene editing would be required, this approach might be a 


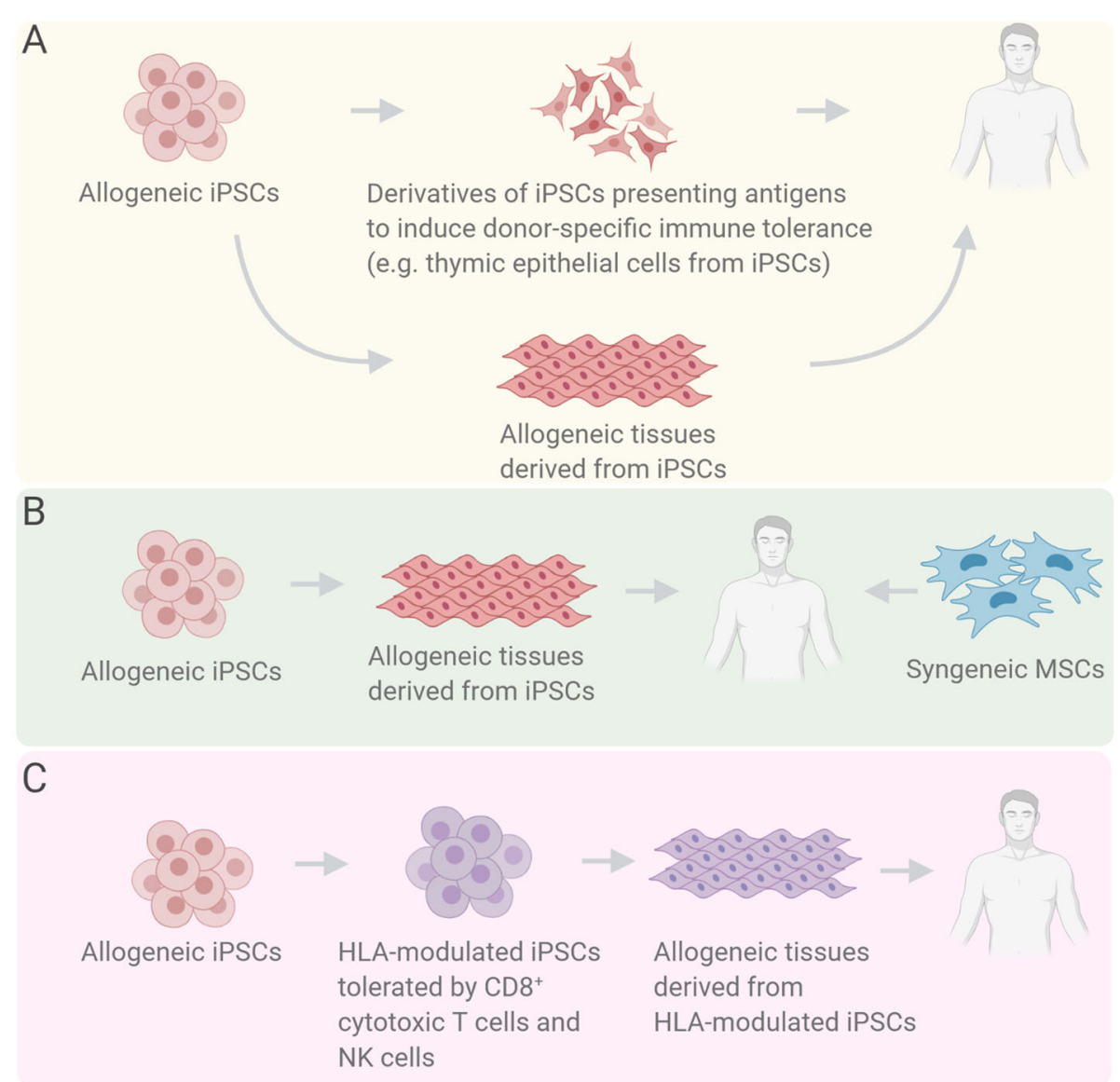

Fig. 2 A schema of various immune regulation approaches. a Transplantation of thymic antigen-presenting cells prior to iPSC-derived allogeneic cells/tissue to induce donor-specific immune tolerance. $\mathbf{b}$ Simultaneous transplantation of iPSC-derived allogeneic cells/tissue and syngeneic mesenchymal stem cells (MSCs) to induce immune tolerance. c Modulation of HLAs of allogeneic iPSCs to circumvent CD8 ${ }^{+}$cytotoxic T cells and natural killer cells (NK cells)-mediated immune responses

promising strategy towards standardization of iPSCbased transplantation medicine.

CRISPR-Cas9 and other gene-editing systems have recently been used to create donor cells that escape interference from the immune system (universal donor cell). As previously described, it is not only possible to genetically modify the expression patterns of HLA class I and class II, but also to apply the immune escape mechanisms that occur in nature, such as cancer cells and placentas, to prevent the expansion of $\mathrm{T}$ cells and NK cells and promote Treg cell responses. Recently, some groups reported the creation of universal donor cells expressing immunomodulatory transgenes that have improved viability in allogeneic transplants [32]. On the other hand, there is a concern in the clinical use of universal donor cells because the universal donor cells might be less sensitive for the elimination through native immune systems in the case of malignant transformation

Table 1 Strategies of immune regulation other than HLA-matching

\begin{tabular}{|c|c|c|c|c|c|}
\hline Author & Strategy & Graft & Recipient & Mechanism of immune tolerance & Ref. \\
\hline $\begin{array}{l}\text { Otsuka } \\
\text { et al. }\end{array}$ & $\begin{array}{l}\text { Transplantation with iPSC-derived } \\
\text { immunogenicity cells }\end{array}$ & Tissues derived from iPSCs & $\begin{array}{l}\text { Allogeneic } \\
\text { animal }\end{array}$ & $\begin{array}{l}\text { iPSC-derived antigens induce donor-specific im- } \\
\text { mune tolerance }\end{array}$ & {$[29]$} \\
\hline $\begin{array}{l}\text { Yoshida } \\
\text { et al. }\end{array}$ & $\begin{array}{l}\text { Transplantation with syngeneic } \\
\text { MSCs }\end{array}$ & Tissues derived from iPSCs & $\begin{array}{l}\text { Allogeneic } \\
\text { animal }\end{array}$ & $\begin{array}{l}\text { Syngeneic MSCs induce Treg cells and the } \\
\text { apoptosis of } \mathrm{CD}^{+} \mathrm{T} \text { cells for graft }\end{array}$ & \\
\hline Xu et al. & Universal cells by genomic editing & $\begin{array}{l}\text { Tissues derived from HLA- } \\
\text { modulated iPSCS }\end{array}$ & $\begin{array}{l}\text { Allogeneic } \\
\text { animal }\end{array}$ & $\begin{array}{l}\text { Inducing tolerances from } \mathrm{CD}^{+} \text {cytotoxic T cells } \\
\text { and NK cells }\end{array}$ & \\
\hline $\begin{array}{l}\text { Rong } \\
\text { et al. }\end{array}$ & Universal cells by genomic editing & $\begin{array}{l}\text { Cells derived from immune- } \\
\text { modified ESCs }\end{array}$ & $\begin{array}{l}\text { Allogeneic } \\
\text { animal }\end{array}$ & The expression of immunomodulatory transgenes & \\
\hline
\end{tabular}


or viral infection. Risk-hedging strategies would be anticipated for the clinical implementation of the universal donor cells such as the transduction of a suicide gene to allow malignantly transformed cells to be eliminated [33].

\section{Considerations for immune regulation on iPSC- based cardiac regenerative therapy through transplantation of bioengineered heart tissue}

Although aforementioned approaches may possibly solve the problems in iPSC-based transplantation immunity, it remains to be further investigated whether these approaches will sufficiently work in iPSC-based cardiac regenerative therapies considering possible severe immunological circumstances of the heart. Another immunological consideration in iPSC-based cardiac regenerative therapies is the possible transition of transplantation subjects from "cells" to "tissue/organoids" [34]. This paradigm shift would be much conceivable in cardiac regenerative therapy because the heart organ works as a pump based on highly organized cell-cell and cell-extracellular matrix assembly, and tissue/organoid structures beyond single cells are required to reproduce heart pump function in future cardiac regenerative therapies.

It also means that immune regulation strategies which would even work in organ transplantation would be required in future iPSC-based cardiac regenerative therapies based on iPSC-derived tissue/organoid transplantation. Given the long history of research on immune rejection in organ transplants [35], it would be predicted that immunosuppressants are somehow required for successful transplantation therapies. It also means that strategies to reduce complications caused by long-term administration of immunosuppressants such as carcinogenesis and infectious diseases [36, 37].

A strategy for the alleviation of immunosuppressantrelated complications is to establish a system that can detect immune rejection in daily clinical practices to precisely control the immunosuppression level (Fig. 3).

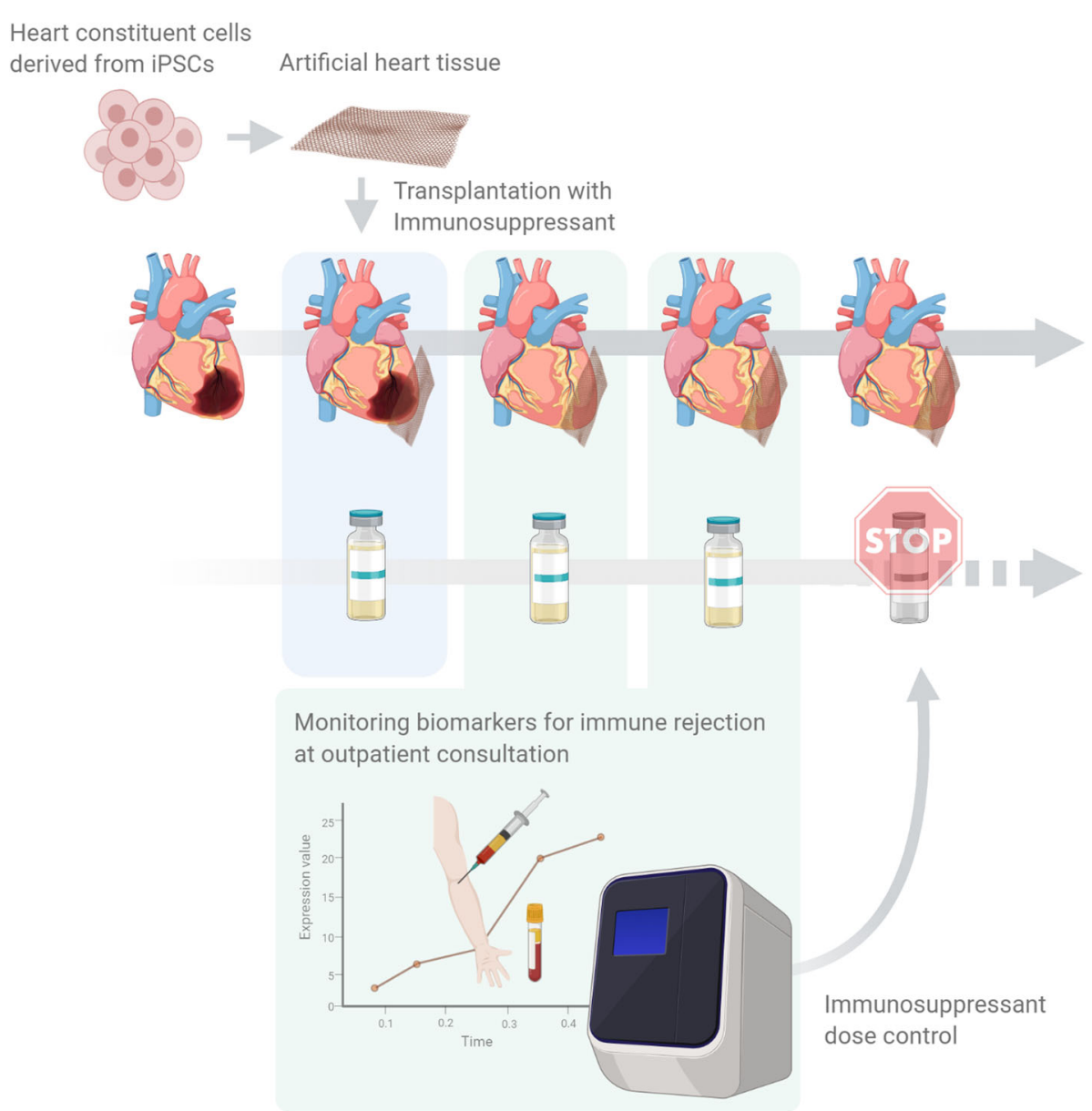

Fig. 3 A scheme of the interventional control for immunosuppressive therapy after iPSC-derived heart tissue transplantation. To establish a system to detect immune rejection in daily clinical practices, identification of biomarkers reflecting immune rejection would be anticipated by histological and biochemical evaluations for samples with various immune rejection level 
To construct this system, It is necessary to identify specific biomarkers which indicates the occurrence of immune rejection which is not identified so far in the field of iPSC-based transplantation therapy. It is presumed that histological and biochemical evaluations for samples with various immune rejection level controlled by MHC-matching and dose of immunosuppressants obtained through allogeneic transplant model experiments would contribute to identify biomarkers to detect immune rejection dedicated for pluripotent stem cell transplantation therapy. Interventional control of immunosuppression level in clinics using the detection system might provide safer iPSC-based tissue/organoid transplantation therapies for heart diseases.

\section{Conclusion}

In the present review, we introduced present status and possible immunological problems in iPSC-based transplantation therapies including ongoing research attempts for immune regulation such as production of "cells that control the immune system" and "cells that get past the immune system." Further investigations on immune regulation are required for standardization of iPSCderived cardiac regenerative therapy based on distinctive features of iPSC-based tissue/organoid transplantation of the heart.

\section{Acknowledgements}

None.

\section{Authors' contributions}

K.Murata. and H.M. wrote the manuscript. M.I., K.Minatoya, and H.M. supervised the research. The authors read and approved the final manuscript.

\section{Funding}

AMED under Grant Number 20bm0404029h0103 (to H.M.).

\section{Availability of data and materials}

Not applicable.

\section{Ethics approval and consent to participate}

Not applicable.

\section{Consent for publication}

Obtained.

\section{Competing interests}

The authors declare that they have no competing interests.

\section{Author details}

${ }^{1}$ Clinical Translational Research Program, RIKEN Center for Biosystems Dynamics Research, 2-2-3 Minatojima-minamimachi, Chuo-ku, Kobe, Hyogo 650-0047, Japan. ${ }^{2}$ Institute for Advancement of Clinical and Translational Science, Kyoto University Hospital, Kyoto, Japan. ${ }^{3}$ Department of Life and Medical Systems, Faculty of Life and Medical Sciences, Doshisha University, Kyoto, Japan. ${ }^{4}$ Department of Cardiovascular Surgery, Graduate School of Medicine, Kyoto University, Kyoto, Japan.
Received: 17 July 2020 Accepted: 9 September 2020

Published online: 29 September 2020

\section{References}

1. Virani SS, Alonso A, Benjamin EJ, et al.: Heart disease and stroke statistics - 2020 update: a report from the American Heart Association. 2020.

2. Mangini $S$, Alves BR, Silvestre OM, et al. Heart transplantation: review. Einstein (Sao Paulo). 2015;13:310-8.

3. Desai SR, Hwang NC. Advances in left ventricular assist devices and mechanical circulatory support. J Cardiothorac Vasc Anesth. 2018;32: 1193-213.

4. Nakatani T, Fukushima $N$, Ono $M$, et al. The registry report of heart transplantation in Japan (1999-2014). Circ J. 2015:80:44-50.

5. Bergmann O, Bhardwaj RD, Bernard S, et al. Evidence for cardiomyocyte renewal in humans. Science (80- ). 2009:324:98-102.

6. Domae K, Miyagawa S, Toda K, et al. New treatment strategy for severe heart failure: combination of ventricular assist device and regenerative therapy. J Artif Organs. 2020. https://doi.org/10.1007/s10047-020-01185-w REVIEW Tissue.

7. Sawa Y, Yoshikawa Y, Toda K, et al. Safety and efficacy of autologous skeletal myoblast sheets (TCD-51073) for the treatment of severe chronic heart failure due to ischemic heart disease. Circ J. 2015:79:992-9.

8. Mazzola M, Di Pasquale E. Toward cardiac regeneration: combination of pluripotent stem cell-based therapies and bioengineering strategies. Front Bioeng Biotechnol. 2020;8:455. https://doi.org/10.3389/fbioe.2020.00455.

9. Orlic D, Kajstura J, Chimenti S, et al. Bone marrow cells regenerate infarcted myocardium. Nature. 2001;410:701-5.

10. Meyer GP, Wollert KC, Lotz J, et al. Intracoronary bone marrow cell transfer after myocardial infarction: 5-year follow-up from the randomizedcontrolled BOOST trial. Eur Heart J. 2009;30:2978-84.

11. Perin EC, Willerson JT, Carl J. Pepine ADM. Effect of transendocardial delivery of autologous bone marrow mononuclear cells on functional capacity, left ventricular function, and perfusion in chronic ischemic heart failure: the FOCUS-CCTRN trial. JAMA. 2012;307:1717-26.

12. Hare JM, Fishman JE, Gerstenblith $\mathrm{G}$, et al. Comparison of allogeneic vs autologous bone marrow-derived mesenchymal stem cells delivered by transendocardial injection in patients with ischemic cardiomyopathy. J Autism Dev Disord 2017; 47:549-62.

13. Menasché $P$, Alfieri $O$, Janssens $\mathrm{S}$, et al. The myoblast autologous grafting in ischemic cardiomyopathy (MAGIC) trial: first randomized placebo-controlled study of myoblast transplantation. Circulation. 2008;117:1189-200.

14. Takahashi K, Tanabe K, Ohnuki M, et al. Induction of pluripotent stem cells from adult human fibroblasts by defined factors. Cell. 2007;131:861-72.

15. Sugita S, Iwasaki Y, Makabe $K$, et al. Successful transplantation of retinal pigment epithelial cells from MHC homozygote iPSCs in MHC-matched models. Stem Cell Rep. 2016;7:635-48.

16. Morizane A, Kikuchi T, Hayashi T, et al. MHC matching improves engraftment of iPSC-derived neurons in non-human primates. Nat Commun. 2017:8:1-12.

17. Mandai M, Watanabe $A$, Kurimoto $Y$, et al. Autologous induced stemcell-derived retinal cells for macular degeneration. N Engl J Med. 2017; 376:1038-46.

18. Umekage M, Sato $Y$, Takasu N, et al. Overview: an iPS cell stock at CiRA. Inflamm Regen. 2019;39:17. https://doi.org/10.1186/s41232-019-0106-0.

19. Shiba Y, Gomibuchi T, Seto T, et al. Allogeneic transplantation of iPS cell-derived cardiomyocytes regenerates primate hearts. Nature. 2016; 538:388-91

20. Masumoto $H$, Nakane T, Tinney JP, et al. The myocardial regenerative potential of three-dimensional engineered cardiac tissues composed of multiple human iPS cell-derived cardiovascular cell lineages. Sci Rep. 2016:6:1-10.

21. Matsuo T, Masumoto H, Tajima S, et al. Efficient long-term survival of cell grafts after myocardial infarction with thick viable cardiac tissue entirely from pluripotent stem cells. Sci Rep. 2015;5:1-14.

22. Masumoto $H_{\text {, Ikuno }} \mathrm{T}$, Takeda $\mathrm{M}$, et al. Human iPS cell-engineered cardiac tissue sheets with cardiomyocytes and vascular cells for cardiac regeneration. Sci Rep. 2014:4:1-7.

23. Nakane T, Masumoto H, Tinney JP, et al. Impact of cell composition and geometry on human induced pluripotent stem cells-derived engineered cardiac tissue. Sci Rep. 2017;7:1-13. 
24. Kawamura T, Miyagawa S, Fukushima S, et al. Cardiomyocytes derived from MHC-homozygous induced pluripotent stem cells exhibit reduced allogeneic immunogenicity in MHC-matched non-human primates. Stem Cell Reports. 2016;6:312-20.

25. Iwaisako K, Sakaguchi S. Regulatory T-cell therapy in the induction of transplant tolerance. Japanese J Transplant. 2017;52:483-8.

26. Sakaguchi S, Miyara M, Costantino CM, et al. FOXP3 + regulatory T cells in the human immune system. Nat Rev Immunol. 2010;10:490-500.

27. Yoshitomi M, Koshiba T, Haga H, et al. Requirement of protocol biopsy before and after complete cessation of immunosuppression after liver transplantation. Transplantation. 2009:87:606-14.

28. Nafady-Hego $H$, Li Y, Ohe $H$, et al. The generation of donor-specific CD4+CD25 ++CD45RA+ naive regulatory $T$ cells in operationally tolerant patients after pediatric living-donor liver transplantation. Transplantation. 2010;90:1547-55.

29. Otsuka R, Wada H, Tsuji H, et al. Efficient generation of thymic epithelium from induced pluripotent stem cells that prolongs allograft survival. Sci Rep. 2020;10:1-8

30. Yoshida S, Miyagawa S, Toyofuku T, et al. Syngeneic mesenchymal stem cells reduce immune rejection after induced pluripotent stem cell-derived allogeneic cardiomyocyte transplantation. Sci Rep. 2020;10:1-11.

31. Xu H, Wang B, Ono M, et al. Targeted disruption of HLA genes via CRISPRCas9 generates iPSCs with enhanced immune compatibility. Cell Stem Cell. 2019;24:566-578.e7.

32. Rong Z, Wang $M, H u Z$, et al. An effective approach to prevent immune rejection of human ESC-derived allografts. Cell Stem Cell. 2014;14:121-30.

33. Lanza R, Russell DW, Nagy A. Engineering universal cells that evade immune detection. Nat Rev Immunol. 2019;19:723-33.

34. De Souza N. Organoids. Nat Methods. 2018;15:23.

35. Stolp J, Zaitsu M, Wood KJ. Immune tolerance and rejection in organ transplantation. Methods Mol Biol. 1899:2019:159-80.

36. Hsu DC, Katelaris CH. Long-term management of patients taking immunosuppressive drugs. Aust Prescr. 2009;32:68-71.

37. Girlanda R. Complications of post-transplant immunosuppression Raffaele. Intech. 2012. https://doi.org/10.5772/55614.

\section{Publisher's Note}

Springer Nature remains neutral with regard to jurisdictional claims in published maps and institutional affiliations.

Ready to submit your research? Choose BMC and benefit from:

- fast, convenient online submission

- thorough peer review by experienced researchers in your field

- rapid publication on acceptance

- support for research data, including large and complex data types

- gold Open Access which fosters wider collaboration and increased citations

- maximum visibility for your research: over $100 \mathrm{M}$ website views per year

At $\mathrm{BMC}$, research is always in progress.

Learn more biomedcentral.com/submissions 